University of Nebraska - Lincoln

DigitalCommons@University of Nebraska - Lincoln

Effects of Rearing Density, Age, Sex, and Food Deprivation on Flight Initiation of the Red Flour Beetle (Coleoptera: Tenebrionidae)

Joel Perez-Mendoza

USDA-ARS

James F. Campbell

USDA-ARS, james.campbell@usda.gov

James E. Throne

USDA-ARS, Manhattan, KS, james.throne@ars.usda.gov

Follow this and additional works at: https://digitalcommons.unl.edu/usdaarsfacpub

Perez-Mendoza, Joel; Campbell, James F.; and Throne, James E., "Effects of Rearing Density, Age, Sex, and Food Deprivation on Flight Initiation of the Red Flour Beetle (Coleoptera: Tenebrionidae)" (2011). Publications from USDA-ARS / UNL Faculty. 2032.

https://digitalcommons.unl.edu/usdaarsfacpub/2032

This Article is brought to you for free and open access by the U.S. Department of Agriculture: Agricultural Research Service, Lincoln, Nebraska at DigitalCommons@University of Nebraska - Lincoln. It has been accepted for inclusion in Publications from USDA-ARS / UNL Faculty by an authorized administrator of DigitalCommons@University of Nebraska - Lincoln. 


\title{
Effects of Rearing Density, Age, Sex, and Food Deprivation on Flight Initiation of the Red Flour Beetle (Coleoptera: Tenebrionidae)
}

\author{
JOEL PEREZ-MENDOZA, JAMES F. CAMPBELL, AND JAMES E. THRONE ${ }^{1}$
}

USDA-ARS Center for Grain and Animal Health Research, 1515 College Avenue, Manhattan KS 66502

J. Econ. Entomol. 104(2): 443-451 (2011); DOI: 10.1603/EC10430

\begin{abstract}
Effects of rearing density, adult density and sex ratio in the flight chamber, adult age, sex, presence or absence of food, and duration of food deprivation on rate of and time to flight initiation of the red flour beetle, Tribolium castaneum (Herbst) (Coleoptera: Tenebrionidae), were studied in the laboratory. Rates of flight initiation were slightly lower at lower rearing densities, but they did not differ with age or sex of adults, presence or absence of food in the flight chamber, or duration of food deprivation. Focal adults were less likely to fly when individuals of the opposite sex were present in flight chambers. Presence of the same sex or mixed sexes and numbers of individuals in flight chambers did not affect tendency to fly of focal individuals. Mean time to flight of older beetles (7-20 d old) was less than that of younger beetles ( $1-4 \mathrm{~d}$ old $)$. No young beetles flew during the first $24 \mathrm{~h}$ of flight tests. Mean time to flight did not differ with rearing density, sex, presence or absence of food, or duration of food deprivation. Our results indicate that this species is highly dispersive during the adult stage and that flight does not seem to be associated with just prereproductive or postreproductive dispersal phases, high rearing density, or short to medium periods of food deprivation. Therefore, $T$. castaneum level of flight activity does not seem to be associated with factors that have been shown in the literature to increase dispersal by walking for this species and to increase flight initiation in other stored-product species.
\end{abstract}

KEY WORDS Tribolium castaneum, red flour beetle, flight initiation, rearing density, food deprivation

Dispersal is an important factor in the dynamics of most insect populations because resources in a given habitat are usually time-limited, so dispersal to new habitats is necessary for successful reproduction and survivorship as resources become scarce and insect populations more dense (Dingle 1985). When adults and immatures share common resources, or when they otherwise interfere with one another, the departure of adults can reduce intraspecies competition and thereby promote local population growth (Ziegler 1978). Dispersal also affects the spatial and temporal structure of populations (Kean and Barlow 2000, Kendall et al. 2000, Poethke and Hovestadt 2002). Dispersal both by walking and flight is especially important for stored-product insects that exploit spatially and temporally patchy resources in human food storage and processing facilities. Flight ability of a number of stored-product insect pests has been studied previously (Giles 1969, Sinclair and Haddrell 1985, Wright and Morton 1995) and its role in contributing to infestations demonstrated (Throne and Cline 1994, Ve-

Mention of trade names or commercial products in this publication is solely for the purpose of providing specific information and does not imply recommendation or endorsement by the U.S. Department of Agriculture.

${ }^{1}$ Corresponding author, e-mail: james.throne@ars.usda.gov.
la-Coiffier et al. 1997, Nansen et al. 2001, Campbell and Arbogast 2004, Campbell and Mullen 2004, Toews et al. 2006), but the factors that trigger dispersal by flight have received less attention. The lesser grain borer, Rhyzopertha dominica (F.) (Coleoptera: Bostrichidae), and larger grain borer, Prostephanus truncatus (Horn) (Coleoptera: Bostrichidae), are exceptions because there has been considerable research into factors that trigger flight (Barrer et al. 1993; Aslam et al. 1994; Dowdy 1994; Fadamiro et al. 1996; PerezMendoza et al. 1999a,b) and their dispersal ability (Nansen et al. 2001, Campbell and Hagstrum 2002, Edde and Phillips 2006, Toews et al. 2006).

The red flour beetle, Tribolium castaneum (Herbst) (Coleoptera: Tenebrionidae), is one of the most important pests of cereal flours and other finished products in the world, and its ability to disperse and to colonize new supplies of food has contributed to its status as a pest (Ziegler 1977). T. castaneum disperse readily, and it is one of the first species to find and exploit pristine food patches (Ziegler 1976). The ability of this species to disperse not only by walking but also by flying, probably contributes to this colonization ability. However, much of the research on $T$. castaneum emigration and dispersal has focused on walking behavior. A variety of factors involved in $T$. 
castaneum walking dispersal have been examined, including their ability to disperse within (Surtees 1963, 1964; Hagstrum 1973; Hagstrum and Leach 1973; Parde et al. 2004) and outside patches of food (Hagstrum and Gilbert 1976, Ziegler 1977, Sinclair and Haddrell 1985, Ho and Boon 1995, Campbell and Hagstrum 2002, Romero et al. 2009, Toews et al. 2009); influence of external and internal factors such as age, sex, population density, and food quality and quantity (Ziegler 1976, 1977, 1978; Lavie and Ritte 1980); reproductive fitness benefits of dispersal (Lavie and Ritte 1978); and the genetic basis of dispersal (Ritte and Lavie 1977).

Adult T. castaneum have long been known to fly readily under laboratory conditions if temperatures are warm enough (Zirkle et al. 1988, Cox et al. 2007), and they have been captured flying in and around food storage facilities (Jones 1967, Giles 1969, Sinclair and Haddrell 1985, Boon and Ho 1988, Throne and Cline 1994, Ho and Boon 1995). However, we are not aware of any studies that have evaluated the influence of internal and external factors on $T$. castaneum flight initiation behavior, even though this information is needed to understand the role of these factors in dispersal and colonization behavior in stored grain and processed food facilities. Internal and external factors that have been shown to trigger dispersal by flight in other species of insects have included temperature, sex, age, adult population density, and food. For example, temperature, sex, adult age, food, and adult population density were important factors in flight initiation of Triatoma infestans Klug (Hemiptera: Reduviidae), the main vector of Chagas disease in South America (McEwen et al. 1993, Gurevitz et al. 2006).

Studies on the flight behavior of other stored-product insects have focused on $P$. truncatus and $R$. dominica, two of the most important pests of stored grain. It has been shown that more young (3- to 6-d-old $R$. dominica and less that 32-d-old P. truncatus) beetles reared in high-density cultures initiated flight than older individuals or those from low-density cultures and that the presence or absence of food also exerted a major influence on flight (Barrer et al. 1993, Aslam et al. 1994, Fadamiro et al. 1996, Perez-Mendoza et al. 1999a). Therefore, in this study we examined the effects of rearing and adult density, age, sex, presence or absence of food, and starvation on flight initiation of T. castaneum.

\section{Materials and Methods}

Culture Methods. Insects used in this study were obtained from a colony originally collected from a flour mill in Kansas 5-6 mo before the start of these experiments. Unless otherwise indicated, adults used in the experiments were obtained from stock cultures established by introducing 100 unsexed, 2- to 4-wk-old adults into $200 \mathrm{~g}$ of diet containing 95 parts of wheat flour and five parts of brewer's yeast in quart jars (0.94-liter) and then removing all adults after $3 \mathrm{~d}$. Cultures were maintained at $30 \pm 1^{\circ} \mathrm{C}, 70 \pm 5 \% \mathrm{RH}$, and a photoperiod of 12:12 (L:D) h.

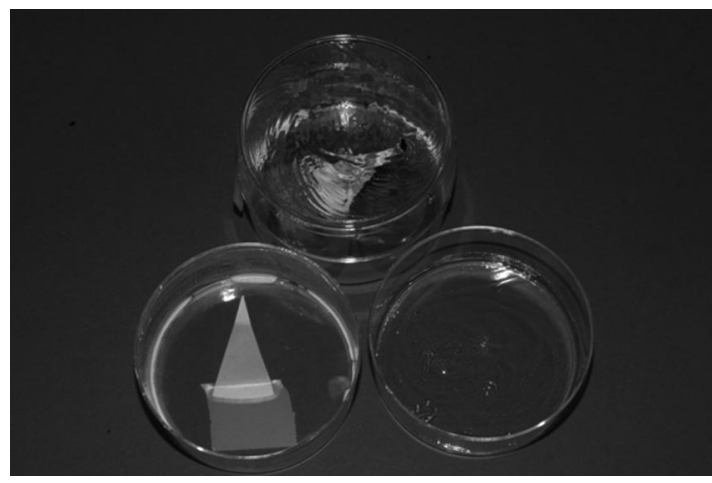

Fig. 1. Chamber used to test flight initiation of T. castaneum showing the upper sticky surface to catch flying beetles and the flight ramp.

Flight Bioassay. Flight initiation was assayed in a flight chamber consisting of the bottom half of a petri dish ( $60 \mathrm{~mm}$ in diameter by $20 \mathrm{~mm}$ in height) (upper dish) with the inner surface coated with sticky material (Sticky Stuff, Olson Products, Medina, OH) inverted over another uncoated petri dish bottom (base dish) of the same dimensions. The sides of the base dish were coated with Teflon PTFE 30 fluorocarbon resin (DuPont, Wilmington, DE) to prevent insects from walking up the sides of the base dish. The base dish was furnished with a platform to facilitate flight initiation. The platform was constructed from a wedge-shaped piece of filter paper cut at a $30^{\circ}$ angle from a 7-cm-diameter filter paper (Whatman International Ltd., Maidstone, England) and taped to the bottom of the base dish at the wide end of the wedge (Fig. 1). The filter paper was folded approximately perpendicularly to the bottom of the dish at $0.5 \mathrm{~cm}$ from the wide end of the wedge and folded again approximately parallel with the bottom of the dish at $2.5 \mathrm{~cm}$ from the wide end. Beetles were able to climb to the point at the end of the platform to initiate flight. Beetles that initiated flight became trapped on the sticky inner surface of the upper petri dish half where they could be counted easily without opening the chamber.

Individual adults were placed in the base dishes without food and immediately covered with the coated upper petri dish. The assembled flight chambers were then placed on plastic trays and held in the laboratory at ambient conditions for $60 \mathrm{~min}$. Then, the trays containing the chambers and insects were transferred to an environmental chamber maintained at $30 \pm 1^{\circ} \mathrm{C}, 70 \pm 5 \% \mathrm{RH}$, and a photoperiod of $12: 12$ (L:D) h, just after lights were turned on. The number of adults that initiated flight (adhered to the sticky surface inside the upper dish) was recorded after 24 , 48 , and $72 \mathrm{~h}$.

Effects of Rearing Density and Adult Age on Flight Initiation. In this experiment, different rearing densities were generated, and the impact of these conditions on flight initiation of first generation progeny was assessed. Different density conditions were created by 
manipulating the number of founding individuals and the length of time they were allowed to oviposit in flour: 20,40 , or 80 unsexed adults were placed on $200 \mathrm{~g}$ of diet (as defined above) in quart jars and removed after 1,2 , or $3 \mathrm{~d}$ ( 20 founding adults) or after $3 \mathrm{~d}$ ( 40 and 80 founding adults). In total, three jars with each density combination were prepared in a completely randomized design with each jar being a replication. The jars were held at $30 \pm 1{ }^{\circ} \mathrm{C}$ and $70 \pm 5 \% \mathrm{RH}$ under a photoperiod of 12:12 (L:D) h. When adult emergence started, jars were sieved daily using a U.S. Standard No. 35 sieve, and the newly emerged adults were transferred to new jars containing the same amount of diet. The developmental time and the total number of adults emerged from each density treatment were recorded. To measure the impact of rearing density and adult age (days after emergence from pupa) on flight initiation, emerged beetles from the five rearing densities were placed individually inside individual flight chambers at $1-4,7-11$, and 16-20 d postemergence from pupae $(n=20$ for each rearing density/ age combination). We selected these age classes because flight initiation occurred only in young adults in previous studies with other stored-product beetles.

Effect of Presence or Absence of Food on Flight Initiation. The effect of presence or absence of food in the flight chambers on flight initiation was tested using sets of beetles from jars founded with 20 adults ovipositing for $48 \mathrm{~h}$ and each of the three age categories described above (1-4, 7-11, and 16-20 d old). Adults from each age category were introduced individually into flight chambers to assess flight initiation, and one set of 20 individuals had $0.25 \mathrm{~g}$ of diet in the chamber and the other set of 20 individuals did not have any food.

Effect of Sex on Flight Initiation. To measure the effect of sex on flight initiation, pupae were obtained from stock cultures and sexed based on size of the papillae (female papillae are larger than those of the male, Park 1934). Adults used in the tests were $25 \pm$ $2 \mathrm{~d}$ in age postemergence from pupae. Sixty males and 60 females were placed individually inside individual flight chambers without food to assess flight initiation.

Effect of Duration of Food Deprivation on Flight Initiation. Beetles used in this experiment were deprived of food for varying periods before testing their flight initiation behavior, and their flight responses were compared with beetles provided with food. Male and female adults were obtained as in the previous experiment. Food-deprived beetles were obtained by placing groups of 40 beetles in petri dishes $(60 \mathrm{~mm}$ in diameter by $20 \mathrm{~mm}$ in height) without food, whereas control beetles were held in petri dishes with $20 \mathrm{~g}$ of diet. The dishes were covered with lids and placed in an environmental chamber at $30 \pm 1{ }^{\circ} \mathrm{C}, 70 \pm 5 \% \mathrm{RH}$, and a photoperiod of 12:12 (L:D) h for $24,48,72,96$, or $120 \mathrm{~h}$. After the holding periods, food-deprived beetles were placed in flight chambers without food, and fed beetles were placed in flight chambers with $0.2 \mathrm{~g}$ of diet. Thirty individual adult males and females were tested for each treatment.
Table 1. Treatments used to evaluate effects of density and sex of accompanying adults on flight initiation of focal male and female adult $T$. castaneum and impact on the percentage of focal adults that flew

\begin{tabular}{|c|c|c|c|}
\hline $\begin{array}{l}\text { Treatment } \\
\text { no. }\end{array}$ & $\begin{array}{l}\text { Sex of focal } \\
\text { adult }\end{array}$ & $\begin{array}{l}\text { No. of and sex of } \\
\text { additional adults present }\end{array}$ & $\begin{array}{l}\% \text { focal adults } \\
\text { that flew }\end{array}$ \\
\hline 1 & $q$ & & 40.0 \\
\hline 2 & t & & 20.0 \\
\hline 3 & q & 10 & 26.7 \\
\hline 4 & 0 & 19 & 3.3 \\
\hline 5 & o & 10 & 23.3 \\
\hline 6 & q & 1 운 & 50.0 \\
\hline 7 & ф & 20 & 26.7 \\
\hline 8 & to & 2 우 & 10.0 \\
\hline 9 & q & 2 ㅇ & 43.3 \\
\hline 10 & o & 20 & 33.3 \\
\hline 11 & o & $4 ㅇ$ & 6.7 \\
\hline 12 & q & 4 o & 16.7 \\
\hline 13 & o & $2 \hat{\sigma}+2$ 우 & 17.0 \\
\hline 14 & q & $2 q+2 \hat{o}$ & 20.0 \\
\hline 15 & o & 4 o & 26.7 \\
\hline 16 & q & 4 운 & 40.0 \\
\hline 17 & o & 8 오 & 13.3 \\
\hline 18 & o & 80 & 43.3 \\
\hline 19 & 0 & 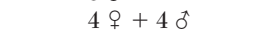 & 20.0 \\
\hline 20 & q & 80 & 20.0 \\
\hline 21 & q & 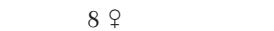 & 66.7 \\
\hline 22 & q & $4 \hat{o}+4$ 우 & 40.0 \\
\hline
\end{tabular}

Effect of Number and Sex of Companion Beetles in Flight Chambers on Flight Initiation of Focal Beetles. The effect of the number and sex of companion beetles in the flight chamber on flight initiation of a focal beetle was studied in this experiment. A focal beetle was placed in a flight chamber, with or without companions, and we determined the impact of nonfocal companion beetles on whether the focal beetle flew, i.e., we did not determine whether nonfocal beetles flew. Flight initiation of focal males and females was tested by placing these individuals in the company of other adults (nonfocal beetles) of varying numbers and sex in the flight chamber without food (treatment combinations are shown in Table 1). Male and female adults were obtained as in the previous experiment. Thirty replicate individual focal adults were tested for flight initiation in each treatment combination. Beetles were marked with a small dot of nail polish on their thorax for identification: focal males (orange), focal females (white), companion males (green), and companion females (pink).

Statistical Analysis. The General Linear Models (PROC GLM) procedure (SAS Institute 2008) and the Ryan-Einot-Gabriel-Welsh (REGWQ) multiple range test were used to determine whether there were significant effects of rearing density treatments on progeny production and developmental time and also to test for differences in time to flight initiation. Differences in untransformed proportion of tested individuals initiating flight during the first $72 \mathrm{~h}$ among different treatments were analyzed using the GLIMMIX procedure with the binary distribution and the Tukey-Kramer multiple range test, except for the experiment with focal beetles where we used single degree of freedom linear contrasts for planned comparisons. 
Table 2. Developmental time and progeny production (mean \pm SE) of $T$. castaneum produced by three densities of adults ovipositing for 24-72 h

\begin{tabular}{ccc}
\hline $\begin{array}{c}\text { Parental density (no. adults } \\
\text { added/oviposition period }[\mathrm{h}] \text { ) }\end{array}$ & $\begin{array}{c}\text { Developmental } \\
\text { time }(\mathrm{d})\end{array}$ & $\begin{array}{c}\text { No. progeny } \\
\text { produced }\end{array}$ \\
\hline $20 / 24$ & $27.4 \pm 0.08 \mathrm{bc}$ & $32.3 \pm 0.3 \mathrm{~d}$ \\
$20 / 48$ & $27.7 \pm 0.04 \mathrm{~b}$ & $178.7 \pm 12.4 \mathrm{c}$ \\
$20 / 72$ & $28.0 \pm 0.04 \mathrm{a}$ & $270.7 \pm 21.5 \mathrm{c}$ \\
$40 / 72$ & $27.7 \pm 0.03 \mathrm{~b}$ & $531.7 \pm 37.8 \mathrm{~b}$ \\
$80 / 72$ & $27.2 \pm 0.02 \mathrm{c}$ & $1094.0 \pm 143.0 \mathrm{a}$ \\
\hline
\end{tabular}

Means within a column followed by different letters are significantly different at $P<0.05$ using the REGWQ test $(n=3)$.

\section{Results}

Effects of Rearing Density and Adult Age on Flight Initiation. There was a biologically insignificant effect of rearing density on developmental time $(F=6.1$; $\mathrm{df}=4,5 ; P=0.04$ ), with developmental times ranging from 27 to $28 \mathrm{~d}$ (Table 2). Numbers of adult progeny produced increased as rearing density increased $(F=$ 55.1; $\mathrm{df}=4,5 ; P<0.01$ ), with progeny production ranging from 32 to 1094 adults (Table 2).

Flight initiation varied among rearing densities $(F=$ $2.8 ; \mathrm{df}=4,285 ; P=0.02$ ) but did not vary with adult age $(F=0.3 ; \mathrm{df}=2,285 ; P=0.77)$, and interaction also was not significant $(F=0.6 ; \mathrm{df}=8,285 ; P=0.78)$ (Fig. 2 ). Although the overall analysis showed differences in flight initiation among densities, no means were significantly different when we used the TukeyKramer multiple range test to control the experimentwise error rate at 0.05 .

The time of flight initiation varied with age of adults $(F=31.9 ; \mathrm{df}=2,131 ; P<0.01)$ but not with rearing density $(F=0.7 ; \mathrm{df}=4,131 ; P=0.56)$, and interaction was not significant $(F=0.6 ; \mathrm{df}=8,131 ; P=0.75)$. The mean time to flight initiation of 1 - to 4 -d-old beetles $(2.6 \pm 0.07 \mathrm{~d})$ was greater than the mean time to flight initiation of 7- to 11-d- and 16- to 20-d-old beetles $(1.8 \pm 0.11$ and $1.5 \pm 0.10 \mathrm{~d}$, respectively) (Table 3). In addition, no beetles in the youngest grouping were observed to fly during the first $24 \mathrm{~h}$ after being added to the flight chamber.

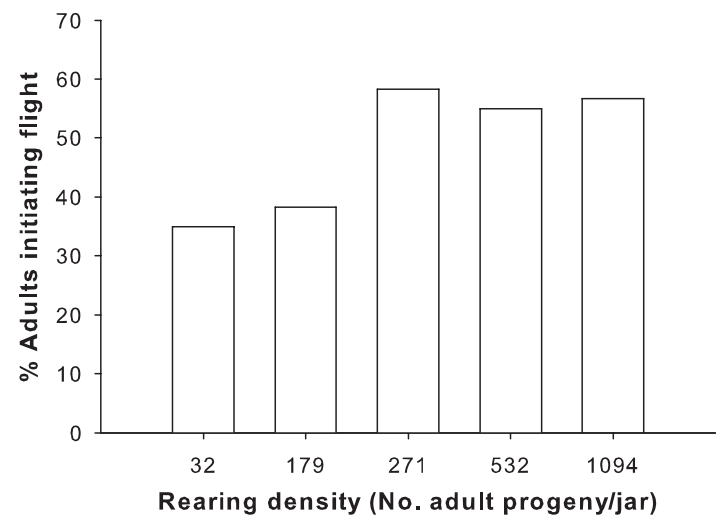

Fig. 2. Effect of rearing density on flight initiation of $T$. castaneum.
Table 3. Effects of density (varying number of parental adults ovipositing for 24,48 , or $72 \mathrm{~h}$ ) and adult age on cumulative percentage of flight initiation of $T$. castaneum after 24,48 , and $72 \mathrm{~h}$

\begin{tabular}{|c|c|c|c|}
\hline \multirow{2}{*}{$\begin{array}{l}\text { Parental density (no. adults } \\
\text { added/oviposition period [h]) }\end{array}$} & \multicolumn{3}{|c|}{ Time of flight initiation $(\mathrm{h})$} \\
\hline & 24 & 48 & 72 \\
\hline \multicolumn{4}{|c|}{ Cumulative $\%$ of 1 - to 4 -d-old adults initiating flight } \\
\hline $20 / 24$ & 0 & 20 & 100 \\
\hline $20 / 48$ & 0 & 20 & 100 \\
\hline $20 / 72$ & 0 & 41.7 & 100 \\
\hline $40 / 72$ & 0 & 53.9 & 100 \\
\hline $80 / 72$ & 0 & 45.5 & 100 \\
\hline \multicolumn{4}{|c|}{ Cumulative $\%$ of 7 - to 11 -d-old adults initiating flight } \\
\hline $20 / 24$ & 37.5 & 100 & 100 \\
\hline $20 / 48$ & 37.5 & 87.5 & 100 \\
\hline $20 / 72$ & 41.7 & 75.0 & 100 \\
\hline $40 / 72$ & 50.0 & 80.0 & 100 \\
\hline $80 / 72$ & 33.4 & 66.7 & 100 \\
\hline \multicolumn{4}{|c|}{ Cumulative $\%$ of 16 - to 20 -d-old adults initiating flight } \\
\hline $20 / 24$ & 62.5 & 100 & 100 \\
\hline $20 / 48$ & 80.0 & 90.0 & 100 \\
\hline $20 / 72$ & 63.6 & 91.0 & 100 \\
\hline $40 / 72$ & 60.0 & 90.0 & 100 \\
\hline $80 / 72$ & 33.3 & 69.7 & 100 \\
\hline
\end{tabular}

Effect of Presence or Absence of Food on Flight Initiation. Flight initiation did not vary with adult age $(F=0.1 ; \mathrm{df}=2,114 ; P=0.91)$ or presence or absence of food in the flight chamber $(F=1.6$; $\mathrm{df}=1,131 ; P=$ 0.22 ) (Fig. 3), and the interaction was not significant $(F=0.03 ; \mathrm{df}=2,131 ; P=0.97)$. The time of flight initiation varied with age of adults $(F=38.9 ; \mathrm{df}=2,57$; $P<0.01)$ but not with presence or absence of food $(F=2.1 ; \mathrm{df}=1,57 ; P=0.15)$, and the interaction was significant $(F=4.4 ; \mathrm{df}=2,57 ; P=0.02)$. Therefore, we determined the effects of presence or absence of food on flight initiation within each age group. The mean time for flight initiation of 1- to 4-d-old adults did not vary with presence or absence of food inside the flight chambers $(F=2.9 ; \mathrm{df}=1,20 ; P=0.11)$. The mean time for flight initiation of adults without food was $2.6 \pm 0.15 \mathrm{~d}$, and the mean time for flight initiation of adults with food was $2.9 \pm 0.10 \mathrm{~d}$. None of the beetles in this age group flew during the first $24 \mathrm{~h}$. The mean time for flight initiation of 7 - to 11-d-old adults

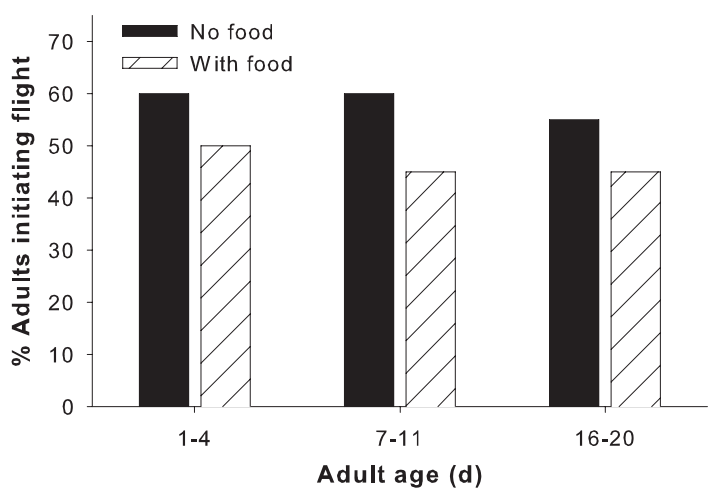

Fig. 3. Effects of age and presence or absence of food in the flight chamber on flight initiation of T. castaneum. 


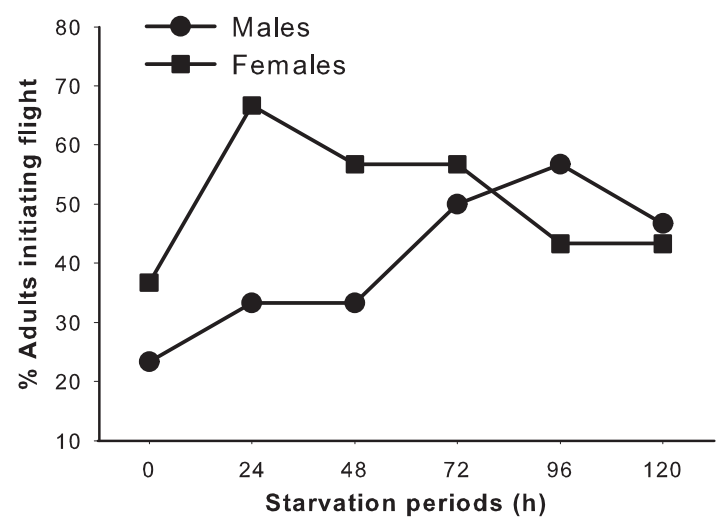

Fig. 4. Effect of duration of food deprivation on flight initiation of adult male and female T. castaneum.

varied with presence or absence of food inside the flight chambers $(F=6.1 ; \mathrm{df}=1,19 ; P=0.02)$. Adults without food delayed flight initiation $(1.8 \pm 0.24 \mathrm{~d})$ relative to adults with food $(1.1 \pm 0.11 \mathrm{~d})$. The mean time for flight initiation of 16 - to 20-d-old adults did not vary with presence or absence of food inside the flight chambers $(F=0.8 ; \mathrm{df}=1,18 ; P=0.40)$. The mean time for flight initiation of adults without food was $1.2 \pm$ $0.15 \mathrm{~d}$, and the mean time for flight initiation of adults with food was $1.5 \pm 0.21 \mathrm{~d}$.

Effect of Sex on Flight Initiation. The percentage of adults initiating flight was similar for males (48.3\%) and females $(53.3 \%)(F=0.3 ; \mathrm{df}=1,118 ; P=0.59)$. The mean time for flight initiation of males and females was the same $(1.8 \pm 0.15 \mathrm{~d})(F=0.01 ; \mathrm{df}=1,58$; $P=0.92$ ).

Effect of Duration of Food Deprivation on Flight Initiation. Flight initiation of adults did not differ with sex $(F=3.8 ; \mathrm{df}=1,348 ; P=0.06)$ or length of food deprivation $(F=1.6$; $\mathrm{df}=5,348 ; P=0.17)$ (Fig. 4$)$, and interaction was not significant $(F=1.7 ; \mathrm{df}=5$, $348 ; P=0.13)$. The time to flight initiation did not differ with sex $(F=0.1$; df $=1,155 ; P=0.96)$ or duration of food deprivation $(F=2.3 ; \mathrm{df}=5,155$; $P=0.06)$, and interaction was not significant $(F=$ $1.1 ; \mathrm{df}=5,155 ; P=0.39)$. The mean time for flight initiation of males and females was $1.35 \pm 0.06$ and $1.38 \pm 0.05 \mathrm{~d}$, respectively.

Effect of Number and Sex of Companion Beetles in Flight Chambers on Flight Initiation of Focal Beetles. In the overall GLIMMIX analysis, the rate of flight initiation of focal adult males and females was significantly affected by different nonfocal beetle numbers and sex $(F=2.9 ; \mathrm{df}=21,638 ; P<0.01)$ (Table 1$)$. The time of flight initiation of focal adults that flew during the flight bioassay did not differ significantly across treatments $(F=1.2 ; \mathrm{df}=21,160 ; P=0.26)$ : overall mean time for flight initiation was $1.3 \pm 0.4 \mathrm{~d}$. We used single degree of freedom linear contrasts (13 contrasts total) and the sequential Bonferroni correction (Rice 1988) to evaluate specific comparisons of rates of flight initiation. Three contrasts were significant after the Bonferroni correction. Combining all the treatment

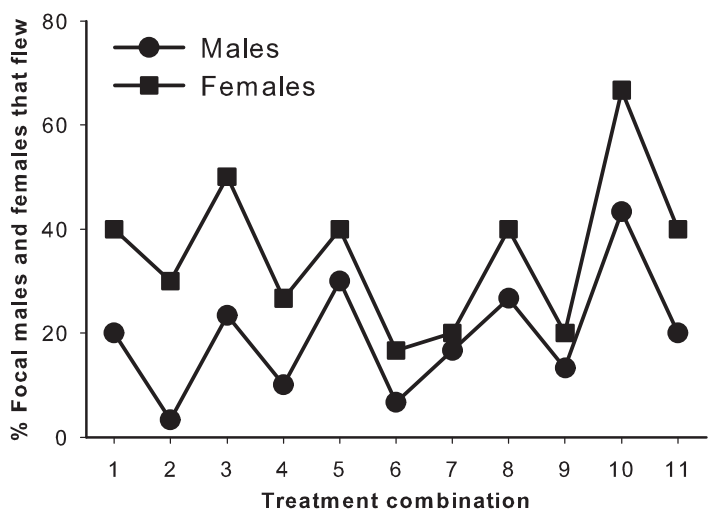

Fig. 5. Rate of flight initiation of focal males and focal females accompanied by varying densities and sexes of nonfocal adult T. castaneum. Treatment combinations are described in Table 1.

combinations, more focal females initiated flight than focal males (Fig. $5 ; F=21.0$; df $=1,638 ; P<0.0001$; $\alpha=0.0038)$. For focal males, rates of flight initiation were lower when paired with only nonfocal females (Fig. 6, dark gray striped bars) than when paired with only nonfocal males (Fig. 6 , light gray bars) $(F=15.6$; $\mathrm{df}=1,638 ; P<0.0001 ; \alpha=0.0042)$. For focal females, rates of flight initiation were lower when paired with only nonfocal males (Fig. 7, dark gray striped bars) than when paired with only nonfocal females (Fig. 7 , light gray bars) $(F=17.2 ; \mathrm{df}=1,638 ; P<0.0001 ; \alpha=$ 0.0045 ).

For focal males, the individual contrast of opposite sex (Fig. 6, dark gray striped bars) versus mixed sex (Fig. 6, white bars) for the nonfocal beetles was not significant after the Bonferroni correction $(F=4.1$; $\mathrm{df}=1,638 ; P=0.04 ; \alpha=0.006$ ). Similarly, the rates of flight initiation of focal females when all nonfocal beetles were opposite sex (Fig. 7, dark gray striped bars) were not significantly different, even without the Bonferroni correction, than the rates of flight initiation of focal females when all nonfocal beetles were mixed sexes (white bars) $(F=0.7$; $\mathrm{df}=1,638 ; P=$ $0.40)$. For both focal males and females, individual comparisons between mixed sex (Figs. 6 and 7, white bars) and same sex nonfocal beetle treatments (Figs. 6 and 7, light gray bars) were not different after Bonferroni correction: focal males $(F=2.8 ; \mathrm{df}=1,638 ; P=$ $0.09)$ and focal females $(F=6.4 ; \mathrm{df}=1,638 ; P=0.01$; $\alpha=0.005$ ).

For both males and female focal beetles, flight initiation was not significantly different when held alone in flight chambers or with other beetles (combining the four different density treatments), regardless of the sex of these nonfocal beetles. The rate of flight initiation of beetles held alone (Figs. 6 and 7, black bar) versus those held with beetles of the same sex (Figs. 6 and 7, light gray bars) was not different for focal males $(F=1.2 ; \mathrm{df}=1,638 ; P=0.27)$ or females $(F=0.9 ; \mathrm{df}=1,638 ; P=0.34)$. Similarly, the rate of flight initiation of focal males $(F=3.6 ; \mathrm{df}=1,638 ; P=$ $0.06)$ and focal females $(F=3.4 ; \mathrm{df}=1,638 ; P=0.07)$ 


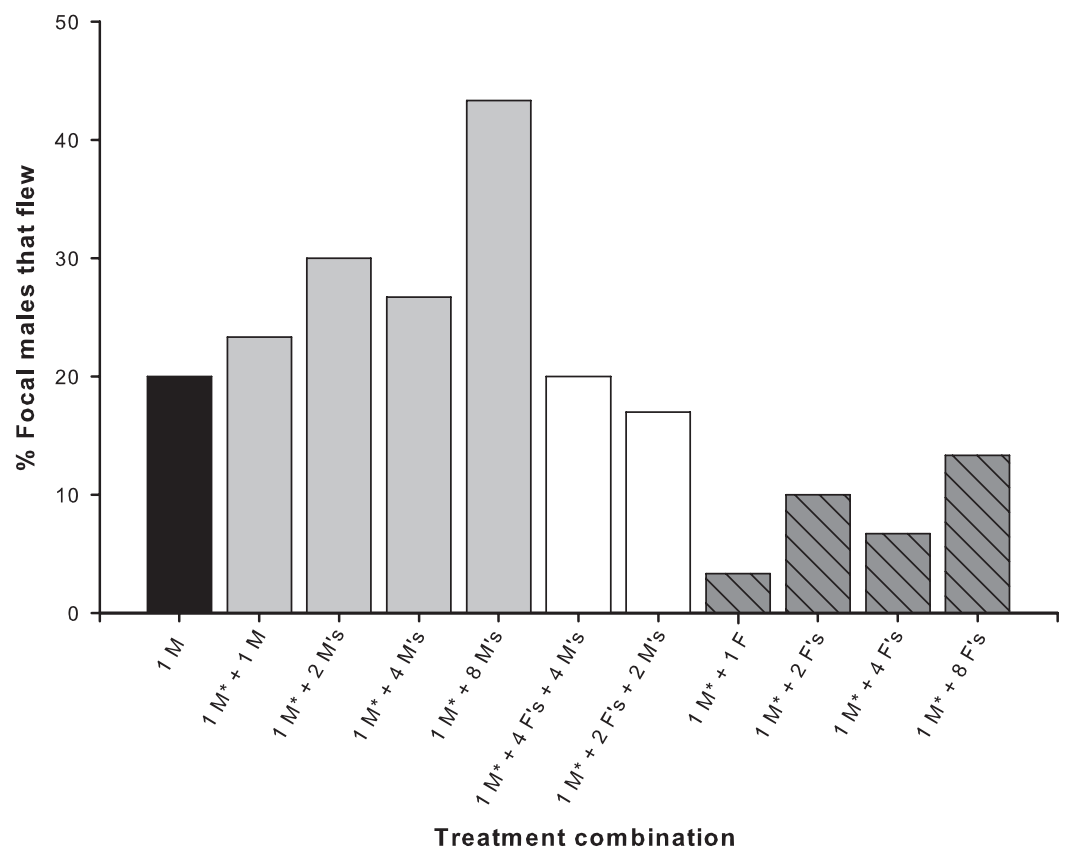

Fig. 6. Effects of number and sex of nonfocal adults on flight initiation of focal male T. castaneum. Focal individual indicated by an asterisk (*).

was not significantly different when held alone (Figs. 6 and 7, black bar) or with nonfocal individuals of the opposite sex (Figs. 6 and 7, dark gray striped bars). Finally, the rate of flight initiation of focal males $(F=$ $0.4 ; \mathrm{df}=1,638 ; P=0.85)$ and focal females $(F=1.0$; df $=1,638 ; P=0.31$ ) when held alone (Figs. 6 and 7 , black bar) was not significantly different than the rates of flight initiation when held with mixed sexes (Figs. 6 and 7 , white bars).

\section{Discussion}

Dispersal usually increases with higher rearing density (Johnson 1966, Denno et al. 1991), but we

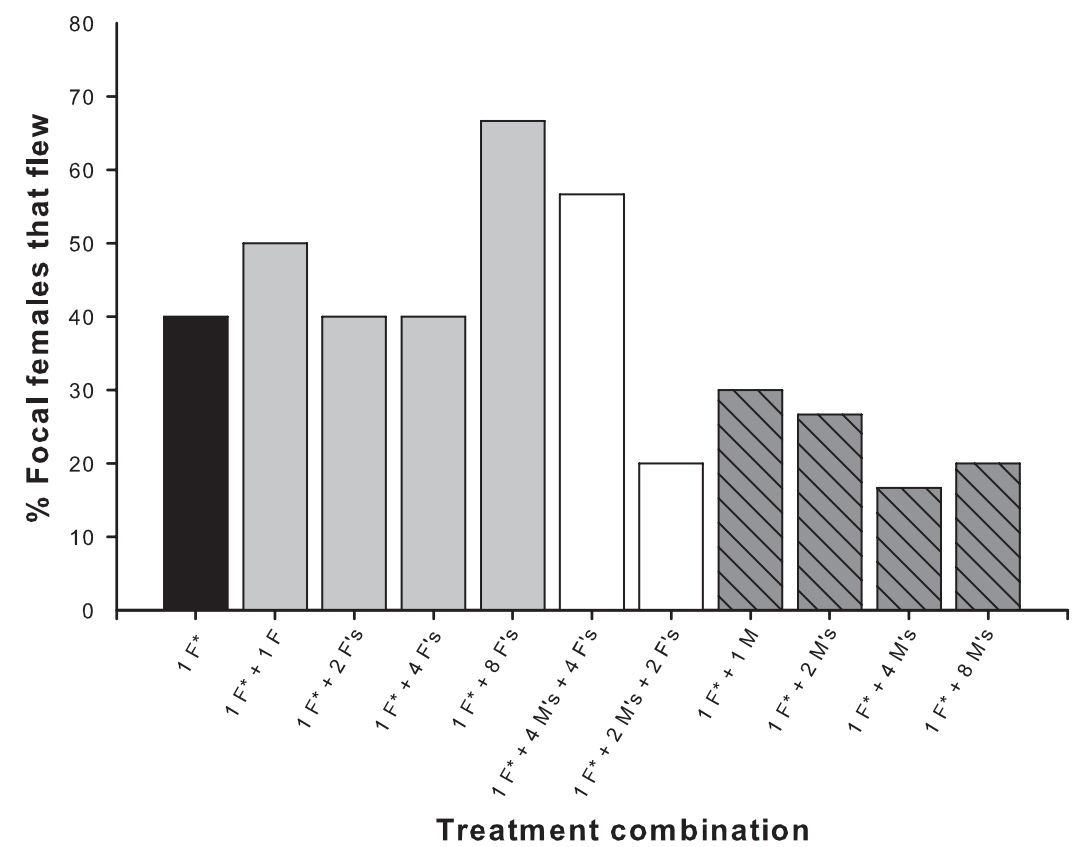

Fig. 7. Effect of number and sex of nonfocal adults on flight initiation of focal female T. castaneum. Focal individual indicated by an asterisk (*). 
did not find a significant increase in flight initiation with rearing density. There was a trend for flight to be greater at higher rearing densities, but means were not significantly different when using the conservative Tukey-Kramer test to control experimentwise error rate. It could be that our rearing densities were not high enough to stimulate an increase in flight initiation, although extremely high rearing densities generated experimentally may not accurately reflect conditions found in the field in which females have the freedom to vary the number of eggs laid depending on the quality and quantity of the food resource. The tendency for crowding during development to increase flight initiation has been reported for other stored-product insects that exploit similar habitats, e.g., R. dominica (Barrer et al. 1993; Perez-Mendoza et al. 1999a,b) and P. truncatus (Fadamiro et al. 1996, Scholz et al. 1997). However, those studies tested the flight initiation ability of adult beetles produced at much higher rearing densities (1-20 or 100-500 founding adults laying eggs for 1-4 wk) than in our study.

The percentage of individuals initiating flight did not vary with age of adults in our study, but younger adults (1-4 d old) took longer to initiate flight than older individuals. This is in contrast with research on R. dominica and P. truncatus. For example, Aslam et al. (1994) and Dowdy (1994) found that more young $R$. dominica adults ( $<1 \mathrm{wk}$ old) initiated flight than older insects ( $>1$ wk old). Similarly, Fadamiro et al. (1996) found that more young $P$. truncatus adults $(8-12 \mathrm{~d}$ old $)$ initiated flight than other ages and older $(>30$-d old $)$ individuals seldom flew, although newly emerged adults (1-3 d old) also seldom flew. Dispersal by walking has been shown in T. castaneum to be influenced by age: Ziegler (1976) reported that emigration was low in sexually immature adults, rose to maximum in early adulthood, and then declined throughout the adult lifespan. However, in our study these changes were not reflected in flight initiation in up to 20-d-old adults. Adult females can live up to $300 \mathrm{~d}$, and adult males can live even longer (Good 1936), so we may not have been able to detect a decline in flight initiation because our oldest adults were $20 \mathrm{~d}$ old.

None of the youngest adults ( $1-4 \mathrm{~d}$ old $)$ flew during the first $24 \mathrm{~h}$ in the flight chambers, whereas peak flight for the oldest beetles occurred during the first $24 \mathrm{~h}$. Greater flight initiation within the first $24 \mathrm{~h}$ in flight tests also was noted by Aslam et al. (1994), who found that one third of the flights by field strains of $R$. dominica adults occurred during the initial $2-4 \mathrm{~h}$ of the flight test. Characteristically, flight is delayed in newly emerged adult insects until the end of the teneral period when the cuticle is hardened (Dingle 1985). Flight also can be delayed until reproductive maturity in some species (Johnson 1966, Ziegler 1976). In T. castaneum, males become sexually mature within $2 \mathrm{~d}$; however, the ovaries of females require $96 \mathrm{~h}$ after adult eclosion to become mature (Bhat 1970). Females typically mate within $2 \mathrm{~d}$ after adult eclosion, but oviposition does not occur until after $96-108 \mathrm{~h}$ after eclosion (Ziegler 1977). Therefore, sexual maturation was oc- curring in the youngest age category that we tested for flight initiation. Our results on flight initiation and results of earlier studies on dispersal and adult age indicate that this species is highly dispersive during the adult stage but that flight does not seem to be associated with just prereproductive or postreproductive dispersal phases or to be tightly linked with changes in walking dispersal reported in the literature.

Although Ziegler (1976) reported differences between the sexes in dispersal ability of young adults, it is not clear whether flight initiation of $T$. castaneum varies with sex. Results from our experiment on effects of sex showed that there was no difference in flight initiation of males and females. However, results from our experiment with focal individuals showed a difference in flight initiation between focal males and females. In other stored-product insect species, no differences in flight initiation between sexes have been reported in $R$. dominica (Dowdy 1994) or $P$. truncatus (Fadamiro et al. 1996).

Food seemed to have little impact on T. castaneum flight initiation. The presence or absence of food in the flight chambers did not affect the rate of flight initiation. This is consistent with other studies on T. castaneum behavior, suggesting limited influence of volatiles associated with flour on walking behavior (Romero et al. 2010). In contrast, Fadamiro et al. (1996) reported that adult $P$. truncatus placed without food inside flight chambers flew more readily than those placed with food. Adult T. castaneum also do not seem to be stimulated to fly in response to short or medium periods without food, although increased flight in response to lack of food has been reported for other stored-product insects. Short periods of starvation (24-72 h) increased flight initiation of R. dominica (Barrer et al. 1993, Perez-Mendoza et al. 1999a) and P. truncatus (Fadamiro and Wyatt 1995).

Interestingly, T. castaneum flight initiation was decreased by the presence of individuals of the opposite sex, regardless of the number, whereas presence of the same sex or mixed sexes did not affect flight initiation. The fitness benefits in terms of potential mating opportunities of this type of response are obvious, but the mechanism generating the response is less clear. Adult males release an aggregation pheromone that attracts both sexes into a food source, and a priori we could predict that the presence of males would suppress female flight, which is what was observed. However, in our study, females also reduced the flight initiation rate of males. This suggests that other sex recognition cues are involved, such as contact cues, visual cues, and/or the presence of sexual pheromones produced by females, which has been demonstrated in confused flour beetles, Tribolium confusum Jacquelin du Duval, whose females produce a sexual pheromone that serves as a short-range attractant to distinguish males from females (Ó’Ceallacháin and Ryan 1977). Naylor $(1959,1961)$ reported that female T. confusum and T. castaneum dispersed more readily when they were in the presence of other females, whereas dispersion was reduced when the sexes were combined. 
The response of T. castaneum to some internal factors was similar to that for other stored-product insects tested to date, but there were also some important differences. Our results indicate that this species is highly dispersive during the adult stage and that flight does not seem to be associated with just prereproductive or postreproductive dispersal phases, rearing density, or to short-to-medium periods without food. Flight initiation in T. castaneum does not seem to be tightly associated with changes in general dispersiveness reported in the literature. Thus, although flight behavior may play an important role in long-range dispersal, by occurring at a relatively steady rate and not responding to density or absence of food, it may not be linked to patterns of movement in and out of food patches associated with patch exploitation. In contrast, adult $P$. truncatus and $R$. dominica increased flight initiation seems more closely associated with an increase in dispersiveness, perhaps because they tend to exploit larger more spatially isolated resource patches than typically used by $T$. castaneum (Campbell and Runnion 2003). T. castaneum is highly adapted to exploit patchily distributed, sparsely populated, and very temporary habitats found inside food facilities by dispersing at any time during its adult life span both before and after the quality of resources in the food patch decreases. The ability to respond to declining resources by more localized search for alternatives, while still having a component of long-range dispersal, may partially explain why this species is one of the most important pests associated with grain processing facilities.

\section{Acknowledgments}

We thank Mark West (ARS, Ft. Collins, CO) for advice and assistance with statistical analyses.

\section{References Cited}

Aslam, M., D. W. Hagstrum, and B. A. Dover. 1994. The effect of photoperiod on the flight activity and biology of Rhyzopertha dominica (Coleoptera: Bostrichidae). J. Kans. Entomol. Soc. 67: 107-115.

Barrer, P. M., N. T. Starick, R. Morton, and E. J. Wright. 1993. Factors influencing initiation of flight by Rhyzopertha dominica (F.) (Coleoptera: Bostrichidae). J. Stored Prod. Res. 29: 1-5.

Bhat, P. N. 1970. Epigenetic studies of the egg in Tribolium castaneum. Tribolium Inf. Bull. 11: 66-67.

Boon, K. S., and S. H. Ho. 1988. Factors influencing the post-fumigation reinfestation of Tribolium castaneum (Herbst) (Coleoptera: Tenebrionidae) in a rice warehouse. J. Stored Prod. Res. 24: 87-90.

Campbell, J. F., and R. T. Arbogast. 2004. Stored-product insects in a flour mill: population dynamics and response to fumigation treatments. Entomol. Exp. Appl. 112: 217225.

Campbell, J. F., and D. W. Hagstrum. 2002. Patch exploitation by Tribolium castaneum: movement pattern, distribution, and oviposition. J. Stored. Prod. Res. 38: 55-68.

Campbell, J. F., and M. A. Mullen. 2004. Distribution and dispersal behavior of Trogoderma variabile and Plodia interpunctella outside a food processing plant. J. Econ. Entomol. 97: 1455-1464.

Campbell,J.F., and C. Runnion. 2003. Patch exploitation by female red flour beetles, Tribolium castaneum. J. Insect. Sci. 3(20). (insectscience.org/3.20.)

Cox, P. D., M. E. Wakefield, and T. A. Jacob. 2007. The effects of temperature on flight initiation in a range of moths, beetles and parasitoids associated with stored products. J. Stored Prod. Res. 43: 111-117.

Denno, R. F., G. K. Roderick, K. L. Olmstead, and H. G. Döbel. 1991. Density-related migration in planthoppers (Homoptera: Delphacidae): the role of habitat persistence. Am. Nat. 138: 1513-1541.

Dingle, H. 1985. Migration, pp. 375-415. In G. A. Kerkut and L. I. Gilbert (eds.), Comprehensive insect physiology, biochemistry and pharmacology, vol. 9. Pergamon, New York.

Dowdy, A. K. 1994. Flight initiation of lesser grain borer (Coleoptera: Bostrichidae) as influenced by temperature, humidity, and light. J. Econ. Entomol. 87: 1714-1717.

Edde, P. A., and T. W. Phillips. 2006. Potential host affinities for the lesser grain borer, Rhyzopertha dominica: behavioral responses to host odors and pheromones and reproductive ability on non-grain hosts. Entomol. Exp. Appl. 119: 255-263.

Fadamiro, H. Y., and T. D. Wyatt. 1995. Flight initiation by Prostephanus truncatus in relation to time of day, temperature, relative humidity and starvation. Entomol. Exp. Appl. 75: 273-277.

Fadamiro, H. Y., T. D. Wyatt, and M. C. Birch. 1996. Flight activity of Prostephanus truncatus (Horn) (Coleoptera; Bostrichidae) in relation to population density, resource quality, age, and sex. J. Insect Behav. 9: 339-351.

Giles, P. H. 1969. Observations in Kenya on the flight activity of stored products insects, particularly Sitophilus zeamais Motsch. J. Stored Prod. Res. 4: 317-329.

Good, N. E. 1936. The flour beetles of the genus Tribolium. U.S. Dep. Agric. Tech. Bull. 498: 1-58.

Gurevitz, J. M., L. A. Ceballos, U. Kitron, and R. E. Gürtler. 2006. Flight initiation of Triatoma infestans (Hemiptera; Reduviidae) under natural climatic conditions. J. Med. Entomol. 43: 143-150.

Hagstrum, D. W. 1973. Infestation of flour by Tribolium castaneum: relationship between distribution of eggs and adults in a dispersing population. Ann. Entomol. Soc. Am. 66: 587-591.

Hagstrum, D. W., and E. E. Gilbert. 1976. Emigration rate and age structure dynamics of Tribolium castaneum populations during growth phase of a colonizing episode. Environ. Entomol. 5: 445-448.

Hagstrum, D. W., and C. E. Leach. 1973. Infestation of flour by Tribolium castaneum: rate of adult dispersal in relationship to sex, mated condition, and other factors. Ann. Entomol. Soc. Am. 66: 384-387.

Ho, S. H., and K. S. Boon. 1995. Spatial distribution of flying Tribolium castaneum (Coleoptera: Tenebrionidae) in a rice warehouse. Bull. Entomol. Res. 85: 355-359.

Johnson, C. G. 1966. A functional system of adaptive dispersal by flight. Annu. Rev. Entomol. 11: 233-260.

Jones, B. E. 1967. Tribolium castaneum (Herbst) (Coleoptera: Tenebrionidae) observed flying from an unusual habitat in Britain. J. Stored. Prod. Res. 3: 185-187.

Kean, J. M., and N. D. Barlow. 2000. The effects of densitydependence and local dispersal in individual-based stochastic metapopulation. Oikos 88: 282-290.

Kendall, B. E., O. N. Bjørnstad, J. Bascompte, T. H. Keitt, and W. F. Fagan. 2000. Dispersal, environmental correla- 
tion, and spatial synchrony in population dynamics. Am. Nat. 5: 628-636.

Lavie, B., and U. Ritte. 1978. The relation between dispersal behavior and reproductive fitness in the flour beetle Tribolium castaneum. Can. J. Genet. Cytol. 20: 589-595.

Lavie, B., and U. Ritte. 1980. Correlated effects of the response to conditioned medium in the flour beetle, Tribolium castaneum. Res. Popul. Ecol. 21: 228-232.

McEwen, P. K., M. J. Lehane, and C. J. Whitaker. 1993. The effect of adult population density on flight initiation in Triatoma infestans (Klug) (Hem., Reduviidae). J. Appl. Entomol. 116: 321-325.

Nansen, C., S. Korie, W. G. Miekle, and N. Holst. 2001. Sensitivity of Prostephanus truncatus (Coleoptera: Bostrichidae) flight activity to environmental variables in Benin, West Africa. Environ. Entomol. 30: 1135-1143.

Naylor, A. F. 1959. An experimental analysis of dispersal in the flour beetle, Tribolium confusum. Ecology 40: 453465

Naylor, A. F. 1961. Dispersal in the red flour beetle Tribolium castaneum (Tenebrionidae). Ecology 42: 231-237.

Ó’Ceallacháin, D. P., and M. F. Ryan. 1977. Production and perception of pheromones by the beetle Tribolium confusum. J. Insect Physiol. 23: 1303-1309.

Parde, S. R., D. S. Jayas, and N.D.G. White. 2004. Movement of adult red flour beetles (Coleoptera: Tenebrionidae) in wheat with pockets of high moisture content. ASAE/ CSAE Annual International Meeting Paper No. 047055. Ottawa, ON, Canada.

Park, T. 1934. Observations on the general biology of the flour beetle Tribolium confusum. Q. Rev. Biol. 9: 36-54.

Perez-Mendoza, J., B. A. Dover, D. W. Hagstrum, and T. L. Hopkins. 1999a. Effect of crowding, food deprivation, and diet on flight initiation and lipid reserves of the lesser grain borer, Rhyzopertha dominica. Entomol. Exp. Appl. 91: 317-326.

Perez-Mendoza, J., D. W. Hagstrum, B. A. Dover, and T. L. Hopkins. 1999b. Flight response, body weight, and lipid content of Rhyzopertha dominica (F.) (Coleoptera: Bostrichidae) as influenced by strain, season and phenotype. J. Stored. Prod. Res. 35: 183-196.

Poethke, H. J., and T. Hovestadt. 2002. Evolution of densityand patch-size-dependent dispersal rates. Proc. R. Soc. Lond. B 269: 637-645.

Rice, W. R. 1988. Analyzing tables of statistical tests. Evolution 43: 223-225.

Ritte, U., and L. Lavie. 1977. The genetic basis of dispersal behavior in the flour beetle Tribolium castaneum. Can. Genet. Cytol. 19: 717-722.

Romero, S. A., J. F. Campbell, J. R. Nechols, and K. A. With. 2009. Movement behavior in response to landscape structure: the role of functional grain. Landscape Ecol. 24: $39-51$.

Romero, S. A., J. F. Campbell, J. R. Nechols, and K. A. With. 2010. Movement behavior of red flour beetle: response to habitat cues and patch boundaries. Environ. Entomol. 39: 919-929.

SAS Institute. 2008. SAS 9.2 for Windows. SAS Institute, Cary, NC.

Scholz, D., C. Borgemeister, R. H. Markham, and H.-M. Poehling. 1997. Flight initiation in Prostephanus truncatus: influence of population density and aggregation pheromone. Entomol. Exp. Appl. 85: 237-245.

Sinclair, E. R., and R. L. Haddrell. 1985. Flight of stored product beetles over a grain farming area in southern Queensland. J. Aust. Entomol. Soc. 24: 9-15.

Surtees, G. 1963. Laboratory studies on dispersion behavior of adult beetles in grain: III.-Tribolium castaneum (Herbst) (Coleoptera, Tenebrionidae) and Cryptolestes ferrugineus (Steph.) (Coleoptera, Cucujidae). Bull. Entomol. Res. 54: 297-306.

Surtees, G. 1964. Laboratory studies on dispersion behavior of adult beetles in grain: VI.-Three-dimensional analysis of dispersion of five species in a uniform bulk. Bull. Entomol. Res. 55: 161-171.

Throne, J. E., and L. D. Cline. 1994. Seasonal flight activity and seasonal abundance of selected stored-product Coleoptera around grain storages in South Carolina. J. Agric. Entomol. 11: 321-338.

Toews, M. D., J. F. Campbell, F. H. Arthur, and S. B. Ramaswamy. 2006. Outdoor flight activity and immigration of Rhyzopertha dominica into seed wheat warehouses. Entomol. Exp. Appl. 121: 73-85.

Toews, M. D., F. H. Arthur, and J. F. Campbell. 2009. Monitoring Tribolium castaneum (Herbst) in pilot-scale warehouses treated with $\beta$-cyfluthrin: are residual insecticides and trapping compatible? Bull. Entomol. Res. 99: 121-129.

Vela-Coiffier, E. L., W. S. Fargo, E. L. Bonjour, G. W. Cuperus, and W. D. Warde. 1997. Immigration of insects into on-farm stored wheat and relationship among trapping methods. J. Stored Prod. Res. 33: 157-166.

Wright, E. J., and R. Morton. 1995. Daily flight activity of Trogoderma variabile (Coleoptera: Dermestidae) and Rhyzopertha dominica (Coleoptera: Bostrichidae). J. Stored Prod. Res. 31: 177-184.

Ziegler, J. R. 1976. Evolution of the migration response: emigration by Tribolium and the influence of age. Evolution 30: 579-592.

Ziegler, J. R. 1977. Dispersal and reproduction in Tribolium: the influence of food level. J. Insect Physiol. 23: 955-960.

Ziegler, J. R. 1978. Dispersal and reproduction in Tribolium: the influence of initial density. Environ. Entomol. 7: 149 156.

Zirkle, D. F., P. S. Dawson, and B. Lavie. 1988. An experimental analysis of the genetic relationship among lifehistory traits and emigration behavior in Tribolium castaneum. Oikos 53: 391-397.

Received 30 November 2010; accepted 5 February 2011. 